\title{
DYNAMIC AMPLIFICATION FACTOR FOR BRIDGES WITH SPAN LENGTH FROM 10 TO 35 METERS
}

\author{
Ilze PAEGLITE, Ainars PAEGLITIS, Juris SMIRNOVS \\ Department of Roads and Bridges, Faculty of Civil Engineering, Riga Technical University, \\ Kalku str. 1, LV1658 Riga, Latvia
}

Received 25 June 2014; accepted 24 November 2014

\begin{abstract}
Heavy traffic on the bridge cause not only static effects, but also dynamic effects. These effects can be indicated by different dynamic parameters like - natural frequency, bridge logarithmical decrement, bridge acceleration and dynamic amplification factor (DAF). Dynamic amplification factor is the most widely used parameter, because it shows amplification of the static effects on the bridge structure. Results show that for bridges road surface condition is a very important factor. If road surface contains ice bumps or potholes then heavy traffic driving with low speed can decrease load carrying capacity of a bridge.
\end{abstract}

Keywords: bridge, dynamic load testing, WIM (weight in motion), traffic loads, dynamic amplification factor, bridge natural frequency.

\section{Introduction}

Heavy traffic loads on the European roads increase every year thus speeding up the deterioration of the road pavement and bridge structures. To understand the cause of the deterioration and reconsider bridge load carrying capacity it is important to now the traffic data such as- truck traffic percentage and axle loads. This information can be obtained from weight-in-motion (WIM) technology. This system is widely used in European countries, because it has a relatively low operating cost and necessary data can be recorded without interfering in the traffic.

Vehicle load on bridge cause not only static effects, but also dynamic effects. These effects can be indicated by different dynamic parameters like - natural frequency, bridge logarithmical decrement, bridge acceleration and dynamic amplification factor (DAF). Dynamic amplification factor is the most widely used parameter because it shows how many times static load should be increased to cover additional dynamic effect (Fryba 1996). Dynamic amplification factor has been included in the design codes to incorporate dynamic effects in the design loads for bridges. This is done by multiplying the static live load with a DAF greater than 1 .

Although additional dynamic load usually does not lead to major bridge failures, dynamic vehicle load can cause problems that later contribute to fatigue, surface wear rapid deterioration and cracking of concrete that leads to reinforcement corrosion (Cebon 1999). It decreases bridge lifetime and increase the maintenance cost of the structure.

Purpose of this study is to determine how various bridge parameters and loading conditions influence Dynamic amplification factor (DAF) of Latvian bridges with span length up to $35 \mathrm{~m}$.

\section{Traffic data on the Latvian roads}

Weight-in-motion (WIM) system was installed in Latvia in 2002 in the crossing of the roads A4 and A6 hence it was possible to obtain first data about traffic composition. System worked normally for 6 years, but 
in 2011 sensors were found totally destroyed by the traffic. These data were analysed (Paeglitis, An., Paeglitis, Ai. 2012) and traffic contents obtained.

Data showed that $79.82 \%$ of the traffic were 2 axle vehicles with weight less than $3.5 \mathrm{t}$, second largest group with $21 \%$ were 5 axle vehicles. However 3 axle vehicles that are usually used for bridge dynamic tests in Latvia were $2.14 \%$ with axle distance about $3 \mathrm{~m}$ and vehicle weight didn’t exceed $30 \mathrm{t}$.

\section{Bridges in Latvia}

Currently there are 936 bridges on the Latvian national road network, of which: 880 are reinforced concrete bridges, 16 are stone and brick, 33 are steel bridges and seven are timber bridges. Regular bridge inspections have shown that about $60 \%$ of the bridges in service have varying degrees of damage that affects the bridge load-carrying capacity. Bridge dynamic tests are performed for even and uneven pavement hence it is possible to find influence of uneven pavement to the bridge dynamic properties.

This paper presents 13 reinforced concrete slab bridge and pre-stressed concrete bridge dynamic load test results performed from 2002 to 2012. For all the bridges were performed analytical calculation of the natural frequency hence it is possible to compare calculated results with the field test results.

\section{Dynamic load testing}

There are different ways to excite the structure - eccentric mass shakers, sudden release of static load, but most reliable way to obtain a bridge dynamic characteristics including Dynamic amplification factor is to use full-scale dynamic testing under controlled or normal traffic conditions. Static and dynamic load test is a part of acceptance procedure for new bridges in Latvia and in many other countries around the world (Burdet, Corthay 1995; Karoumi, Andersson 2007; Cunha et al. 2008; Brencic, Sabia 2007; Akimovs, Paeglītis 2008; Paeglite, Paeglitis 2013). The bridge load testing in Latvia is performed according to the requirements of the national standard LVS 190-11: 2009 Bridge inspection and load testing". The dynamic load tests provide information about the natural frequency and damping of the bridge including the variations of the DAF depending on vehicle speed and pavement condition.
As a dynamic load is usually used a loaded heavy truck with weight around $25 \mathrm{t}$ and 2 or 3 axles. The passage of a loaded truck makes the most real effect of the structure hence it gives the reasonably accurate dynamic results.

The vibration responses were obtained by vibration sensor Noptel PSM-200, that is based on a laser transmitter and an optoelectronic receiver (Fig. 1) connected to the object. Example of obtained vibration responses are given in Figure 2. The operator directs the safe, visible laser beam at the receiver and locks it in a steady position. The receiver recognizes the beam on the optical screen and measures its position accurately up to 500 times a second. The transmitter can be placed at a distance of 1 to 350 meters from the receiver, depending on the environmental conditions.

Instruments were placed in the middle of the tested span. Dynamic properties of the bridge were found from the vibration response diagrams.

The dynamic load test include the vehicle driving over the bridge at two different roadway condition even roadway and uneven with speed of $20 \mathrm{~km} / \mathrm{h}$ and $40 \mathrm{~km} / \mathrm{h}$. Uneven pavement is used to model damages (damaged pavement or ice caused bumps) on it. The bumps in the pavement surface will be modelled with timber planks approximately $5 \mathrm{~cm}$ high and $10 \mathrm{~cm}$ wide installed on the path of the vehicles. The length of the planked roadway depends on the length of the span and could cover approximately $2 / 3$ of it. The distance between the planks is approximately 3 to $3.5 \mathrm{~m}$ but it depends on the distance between vehicle axles.

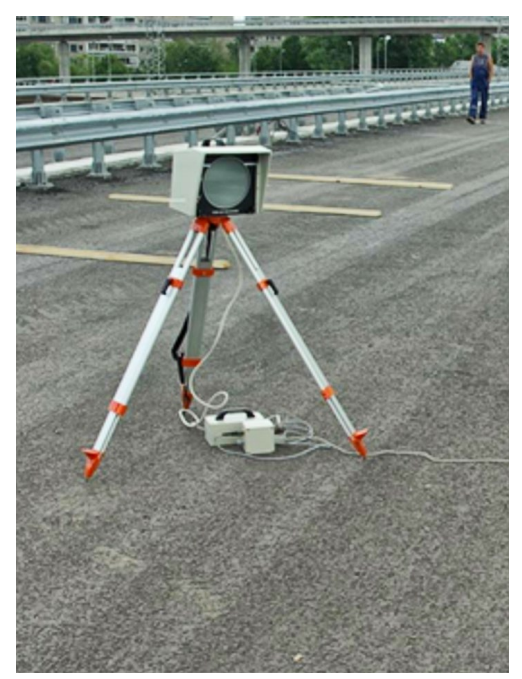

Fig. 1. The vibration sensor Noptel PSM-200 


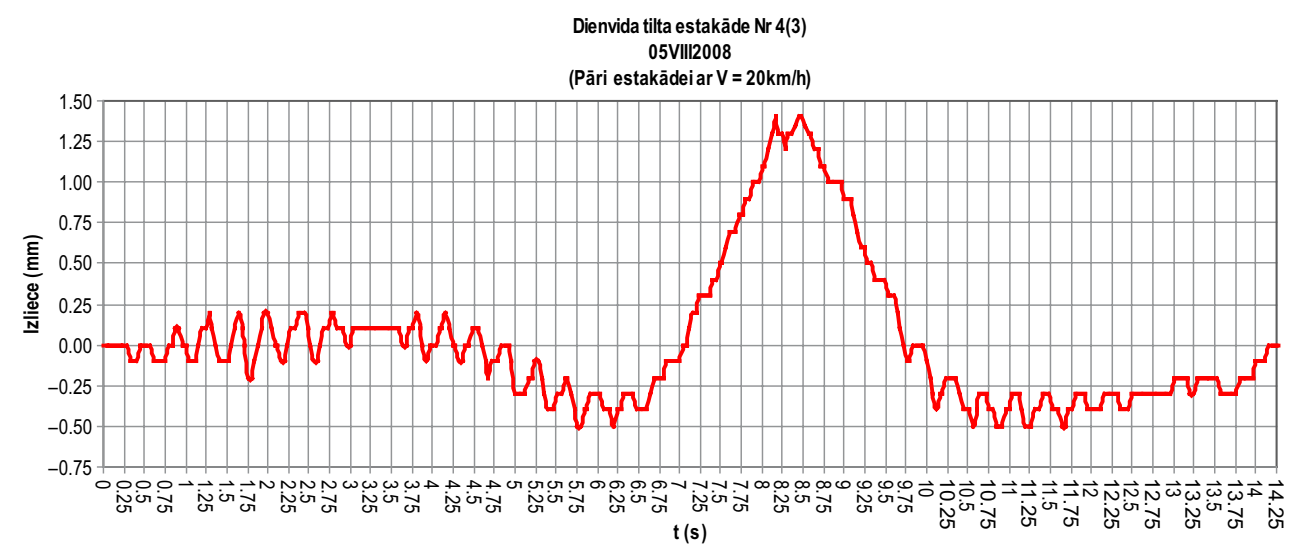

Fig. 2. The vibration response diagram obtained by the Noptel PSM-200

\section{Dynamic parameters}

Dynamic effects on the bridge can be indicated by different dynamic parameters. Most common used are bridge natural frequency, bridge logarithmical decrement and bridge acceleration and dynamic amplification factor (DAF). Bridge codes consider DAF as most useful parameter; hence DAF is introduced in the bridge design codes. The DAF of a bridge is used to describe the ratio between maximum load effect from dynamically loaded bridge and maximum load effect when a bridge is loaded statically (Brady et al. 2006):

$$
D A F=\frac{\varepsilon_{(d y n)}}{\varepsilon_{(s t a t)}},
$$

where $\varepsilon_{(\text {stat })}$ - maximum static response (stress strain of deflection), $\varepsilon_{(d y n)}-$ maximum dynamic response (stress strain of deflection).

Many studies have already been made to determine vehicle and bridge interaction and influence of the DAF on the bridge behaviour (O'Brien et al. 2009; Paulter et al. 1992; Gonzalez et al. 2008). The DAF is an important parameter in the design of the highway bridges and shall be taken into account by the evaluation of the bridge load carrying capacity. The value of the DAF depend on many factors: bridge span length and natural frequency, from the vehicle speed, weight and dynamic characteristics, the condition of the bridge structures - roadway roughness, expansion joint's condition and others. In general, in codes the DAF is given as a function of the bridge span length. However, the obtained load test results showed DAF dependence on the road surface conditions, vehicle weight and passing speed.

In the Eurocode 1 (EN 1991-2:2003 Actions on structures. Traffic loads on bridges) a generalized DAF value should be applied to the worst static load case. DAF values included in load models depend only on the shape of the influence line and bridge length (Cantero et al. 2009). The DAF values used in the Eurocode 1 for 2 -line bridge roadway are presented in the Figure 3. These values are conservative and are acceptable for new bridges because of uncertainty of future traffic growth.

In the previous Structural Codes used in Latvia (SNIP 2.05.03-84), the DAF $(1+\mu)$ values for reinforced concrete bridges could be obtained from the formula (2):

$$
(1+\mu)=1+\frac{45-\lambda}{135}
$$

where $\lambda$ - span length or loaded lengths of the influence line. Formula (2) used to calculate DAF for reinforced concrete bridges showed that the DAF value depends only on the length of the loaded influence line. It shows that the dynamic effects applied to the bridge decreases with the enlargement of the span length. The graphical interpretation of the DAF for various bridge span lengths is given in Figure 4.

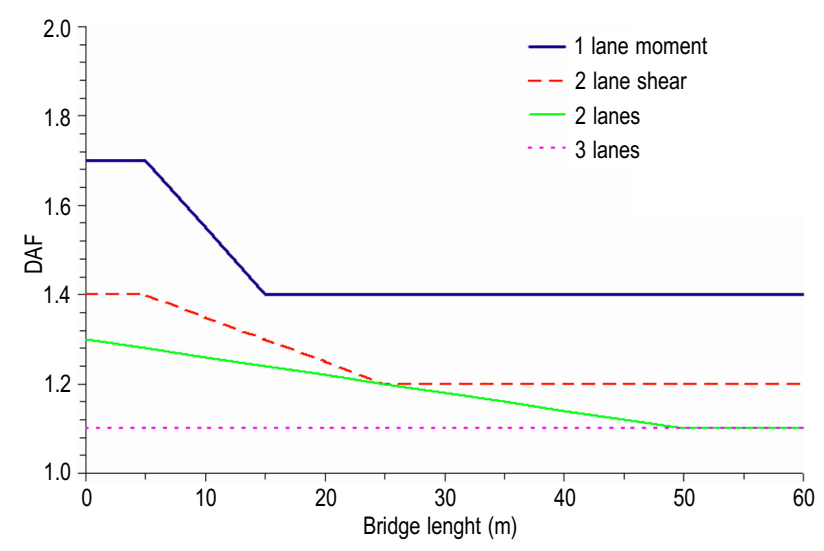

Fig. 3. DAF - dynamic amplification factor built-in values in the Eurocode 1 (Bruls et al. 1996) 


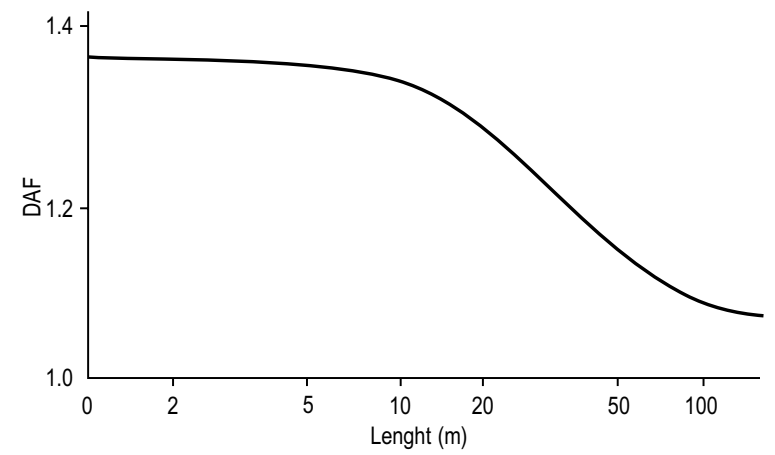

Fig. 4. DAF values from the Structural Codes (SNIP 2.05.03-84) previously used in Latvia (Gonzalez et al. 2009)

Natural frequency for two to three span structures can be found if the stiffness and mass of the structure is given (Beards 1996):

$$
f=\frac{\pi}{2 \cdot L^{2}} \sqrt{\frac{E I}{m}},
$$

where $L$ - span length, $E I$ - structure stiffness, $m$ mass of the span.

For considered bridges natural frequency and period was calculated using FEM software LIRA. In most cases measured bridge natural frequency did not reach calculated first mode bridge natural frequency.

\section{Bridge characteristics}

In this research 8 pre-stressed concrete bridges and 5 reinforced concrete slab bridges were discussed.

Pre-stressed concrete bridges have span length from 20 to $34 \mathrm{~m}$. Discussed bridge span length, calculated and measured natural frequency are given in Table 1. All bridges are new and have concrete class C40/50 XF4 hence concrete cracking was not considered. Bridge cross sections and FEM 3D models are given in Figures 5 to 12.

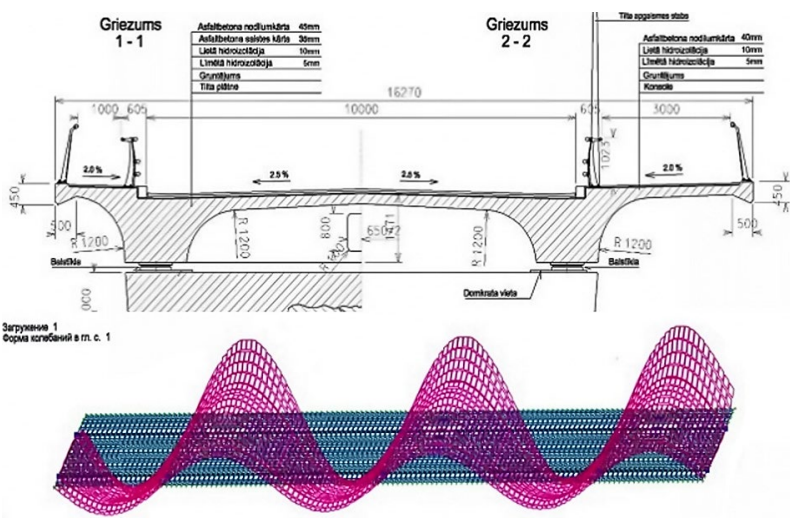

Fig. 5. Cross section and first mode shape of a bridge over river Gauja on road A3. FE model constructed as a plate-strut $3 \mathrm{D}$ system
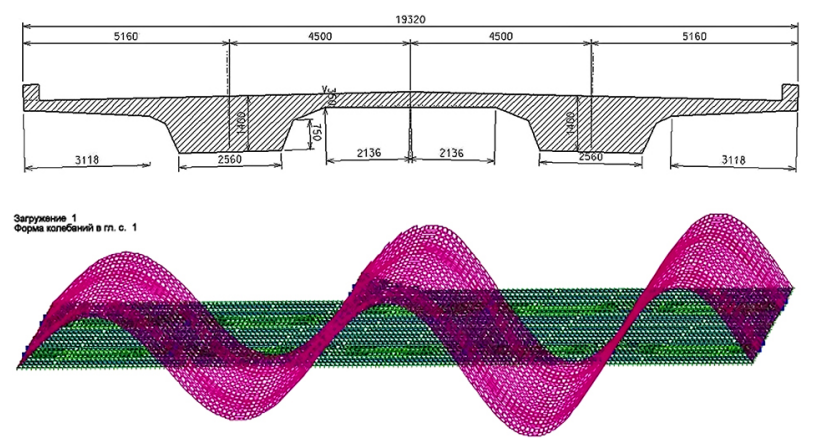

Fig. 6. Cross section and first mode shape of a South bridge overpass Nr. 4-3. FE model constructed as a plate 3D system
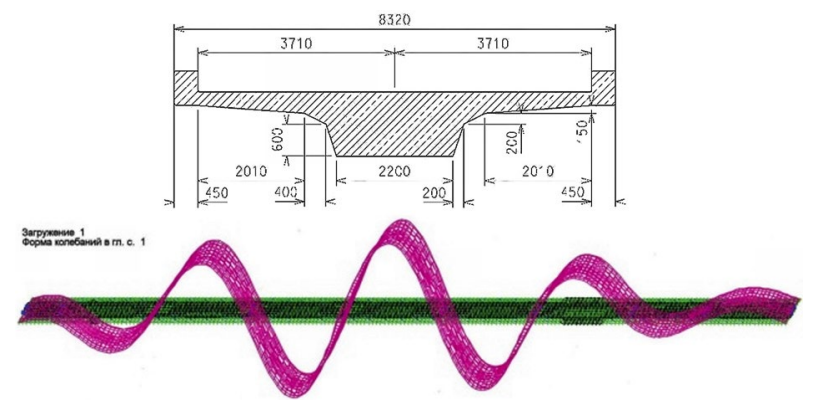

Fig. 7. Cross section and first mode shape of a South bridge overpass Nr. 5-1. FE model constructed as a plate 3D system

Table 1. Characteristic values of pre-stressed concrete bridges

\begin{tabular}{|c|l|c|c|c|}
\hline Nr. & \multicolumn{1}{|c|}{ Name } & $\begin{array}{c}\text { Loaded span } \\
\text { length }\end{array}$ & $\begin{array}{c}\text { Calculated natural } \\
\text { frequency, Hz }\end{array}$ & $\begin{array}{c}\text { Measured natural } \\
\text { frequency, Hz }\end{array}$ \\
\hline 1. & Bridge over river Gauja on road A3 & 22.2 & 4.47 & 5 \\
\hline 2. & South bridge overpass Nr. 4-3 & 32 & 2.11 & 2.38 \\
\hline 3. & South bridge overpass Nr. 5-1 & 24 & 3.27 & 2.75 \\
\hline 4. & South bridge overpass Nr. 5-2 & 24 & 3.38 & 3.7 \\
\hline 5. & South bridge overpass Nr. 7 & 24 & 3.39 & 2.75 \\
\hline 6. & Bridge on A12 over railroad Rīga-Rēzekne & 34 & 2.45 & 3 \\
\hline 7. & Bridge over Rive Dīväja on road A6 & 25.5 & 5.68 & 7.3 \\
\hline 8. & Bridge over Pedele river in Valka & 20.5 & 4.47 & 5.3 \\
\hline
\end{tabular}




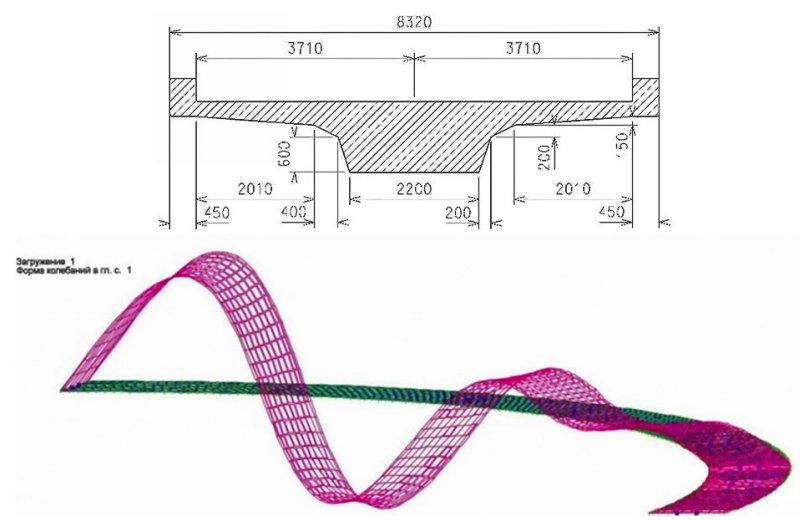

Fig. 8. Cross section and first mode shape of a South bridge overpass Nr. 5-2. FE model constructed as a plate 3D system

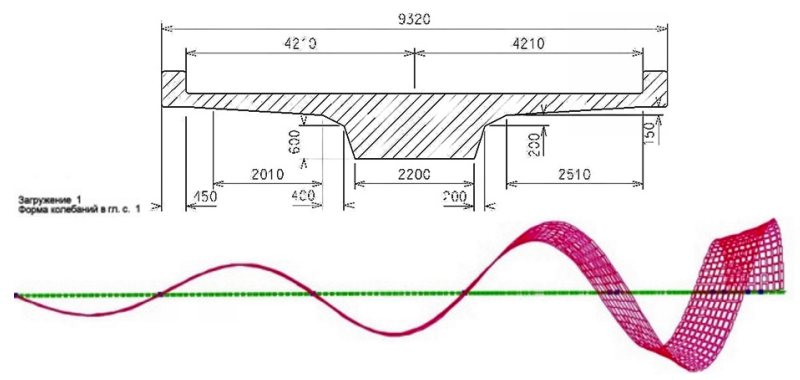

Fig. 9. Cross section and first mode shape of a South bridge overpass Nr. 7. FE model constructed as a plate 3D system

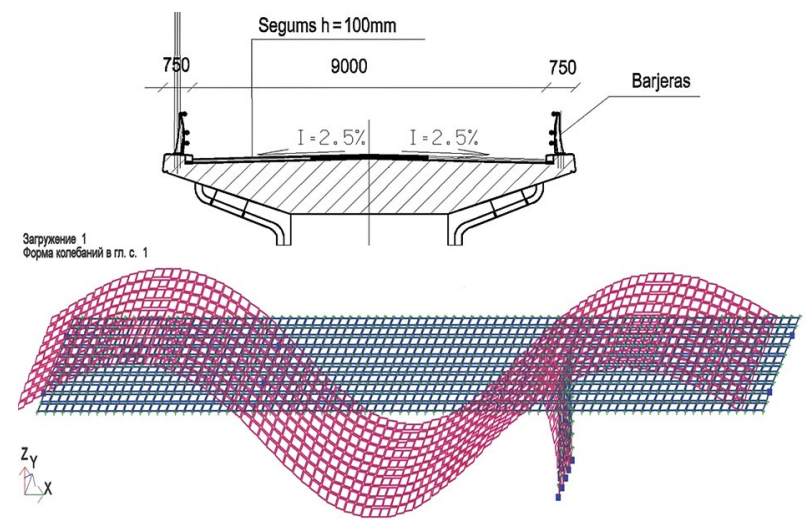

Fig. 10. Cross section and first mode shape of a bridge on A12 over railroad Rìga-Rēzekne. FE model constructed as a plate $3 \mathrm{D}$ system

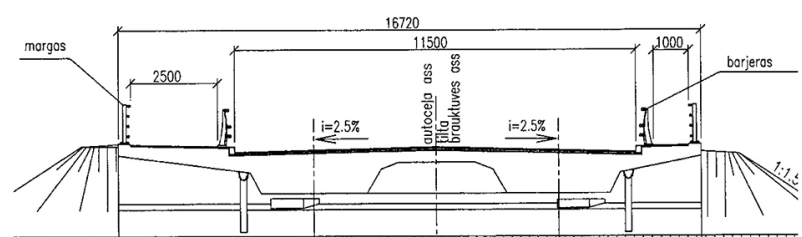

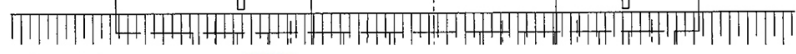

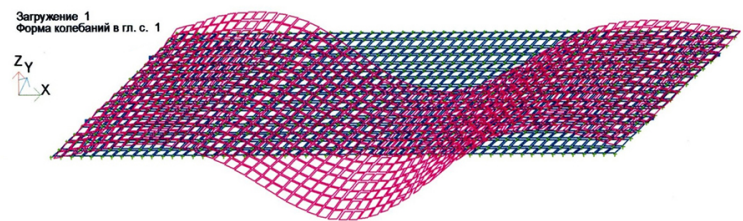

Fig. 11. Cross section and first mode shape of a bridge over Rive Divaaja on road A6. FE model constructed as a plate-strut $3 \mathrm{D}$ system
Concrete slab bridges have span length from 10 to $31 \mathrm{~m}$. All the bridges have continuous systems and were designed using FEM LIRA. All bridges are new and have concrete class C40/50 XF4. Bridge cross sections and FEM 3D models are given in Figures 13 to 16.

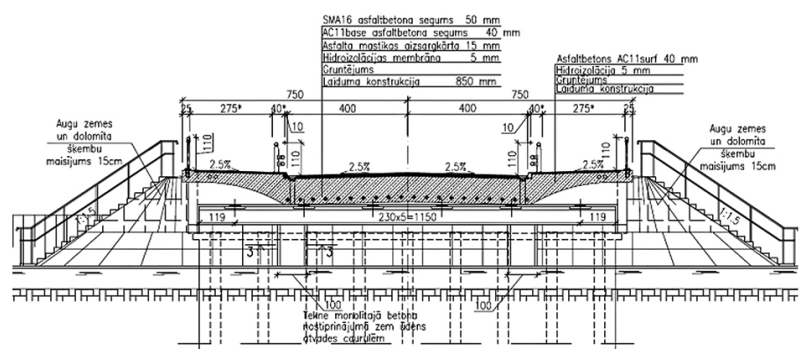

Fig. 12. Cross section of a bridge over Pedele river in Valka. FE model constructed as a plate-strut 3D system

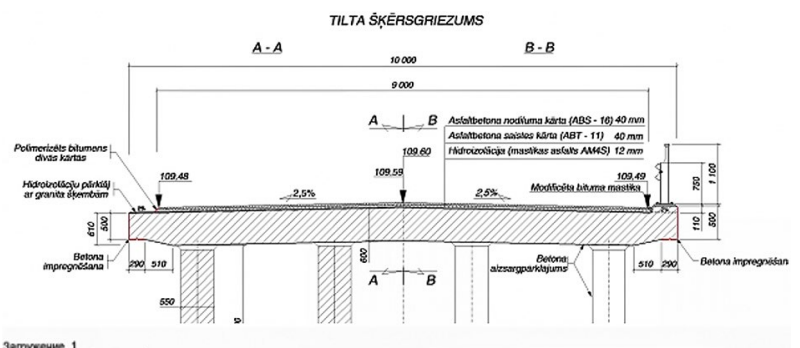

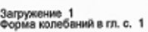

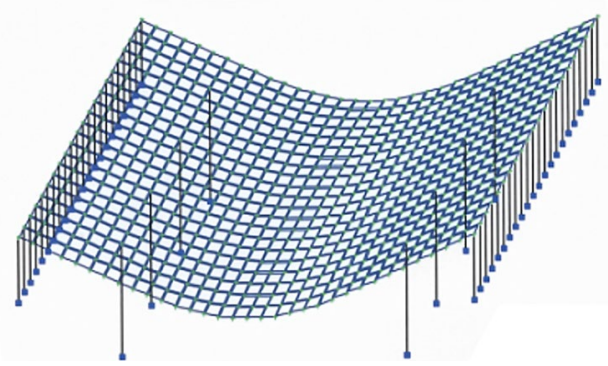

Fig. 13. Cross section and first mode shape of a bridge over river Dzirla on road P035 Gulbene-Balvi. FE model constructed as a plate-strut $3 \mathrm{D}$ system
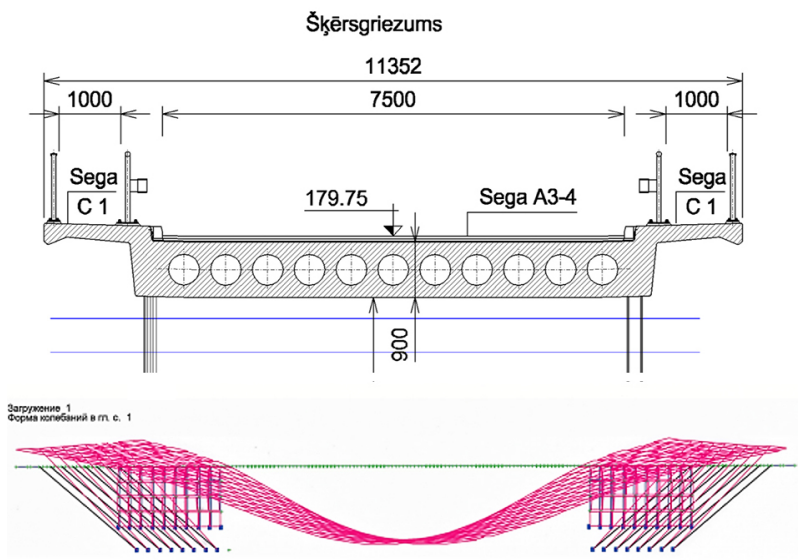

Fig. 14. Cross section and first mode shape of a bridge over river Gauja on Road V235. FE model constructed as a plate-strut $3 \mathrm{D}$ system 


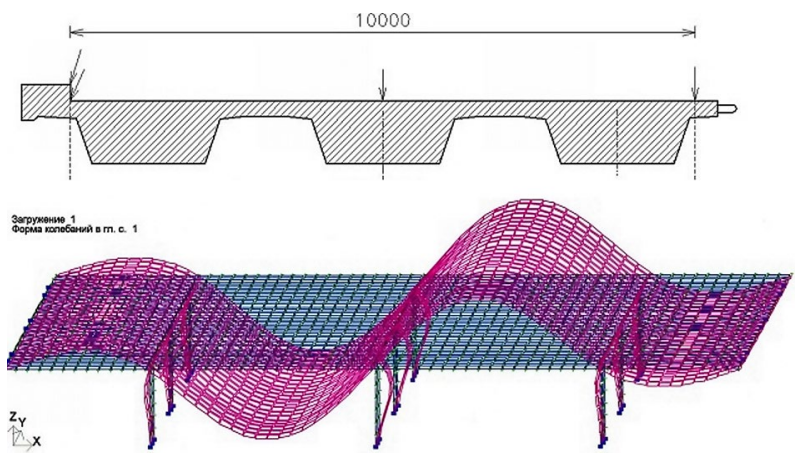

Fig. 15. Cross section and first mode shape of an overpass on road A6 Riga-Belarus border. FE model constructed as a plate-strut $3 \mathrm{D}$ system

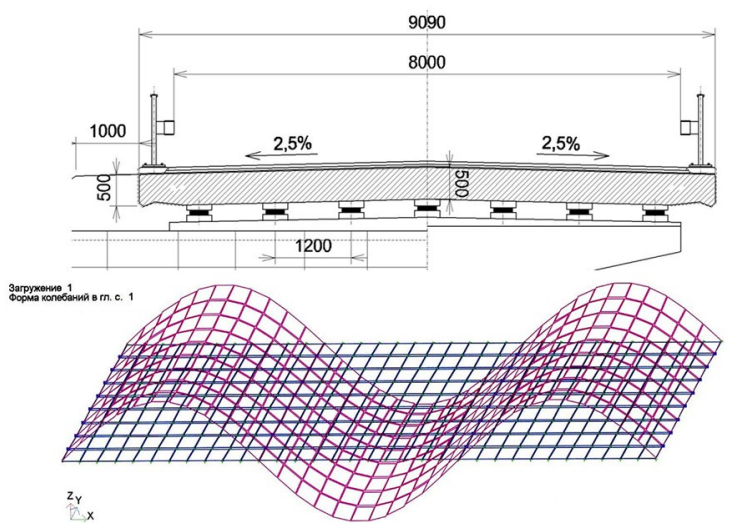

Fig. 16. Cross section and first mode shape of a bridge over Lauce river on P87 Bauska-Aizkraukle. FE model constructed as a plate-strut $3 \mathrm{D}$ system

Table 2. Characteristic values of slab bridges

\begin{tabular}{|c|l|c|c|c|}
\hline Nr. & \multicolumn{1}{|c|}{ Name } & $\begin{array}{c}\text { Loaded } \\
\text { length, } \mathrm{m}\end{array}$ & $\begin{array}{c}\text { Calculated natural } \\
\text { frequency } \\
\text { mode shape) } \mathrm{Hz}\end{array}$ & $\begin{array}{c}\text { Measured natural } \\
\text { frequency, Hz }\end{array}$ \\
\hline 1. & Bridge over river Ludza on road V 535 Kušneri-Plaudiši & 18.3 & 5 & 4.5 \\
\hline 2. & Bridge over river Dzirlas on road P035 Gulbene-Balvi & 10 & 9.78 & 10 \\
\hline 3. & Bridge over river Gauja on Road V235 & 31 & 3.36 & 3.25 \\
\hline 4. & Overpass on road A6 Riga-Belarus border & 19.5 & 5.56 & 6 \\
\hline 5. & Bridge over Lauces river on P87 Bauska-Aizkraukle & 11.41 & 8.88 & 9 \\
\hline
\end{tabular}

\section{Results}

\subsection{Prestressed concrete bridges}

8 discussed bridges are recently built and designed according to Eurocode 1 load model LM1. Natural frequency for structures were calculated using FEM software LIRA and calculated results for first mode shape are given in Table 1. Figure 17 shows that in all cases except one measured natural frequency exceed first mode shape. For bridge Nr. 1 over Gauja natural frequency exceeds second mode shape that can be explained as cross section is most slender.

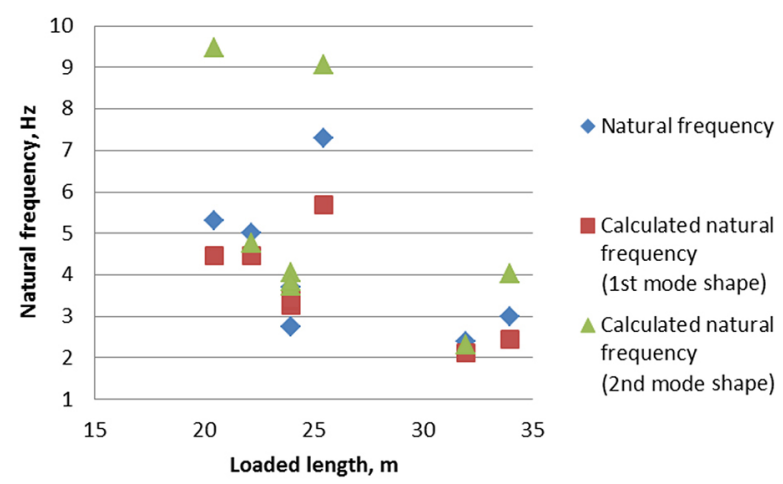

Fig. 17. Natural frequency dependence on loaded length
Figure 18 shows first and second mode shapes for bridge Nr. 7 over Divaja River. For this bridge natural frequency exceeded first mode shape frequency but did not exceed second mode shape. Figure 11 shows cross section of the Bridge Nr. 7.

Figure 19 shows Dynamic amplification factor (DAF) correlation with loaded length. It can be very clearly seen that DAF does not really depends on the span length however it depends on the bridge natural frequency.

Figure 20 shows DAF value dependence on natural frequency, for higher natural frequencies DAF values tend to decrease.

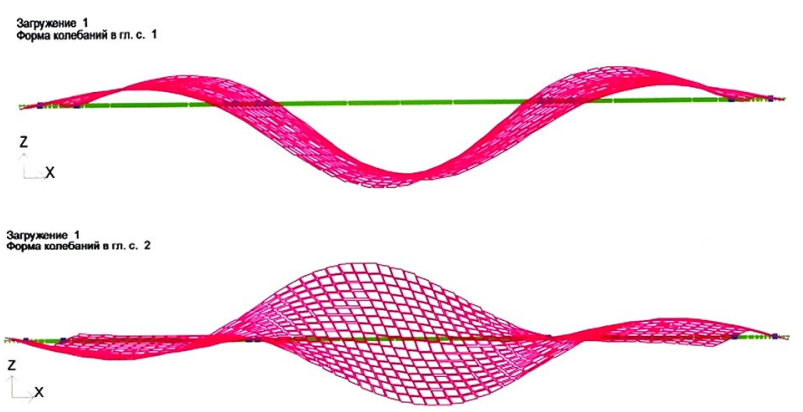

Fig. 18. $1^{\text {st }}$ and $2^{\text {nd }}$ mode shape for bridge over Divaja River 
Figure 19 and Figure 20 show that vehicle speed on uneven pavement strongly influence DAF values. Vehicle crossing bridge over even pavement produce much smaller DAF values than over uneven pavement and moreover, lower speeds over uneven pavement can increase DAF significantly.

This trend should be taken into account for bridge maintenance. Bridge pavement condition should be maintained regularly or traffic can cause damage to the structure.

\subsection{Reinforced concrete slab bridges}

5 discussed reinforced concrete slab bridges were designed according to the Eurocode 1 load model LM1.

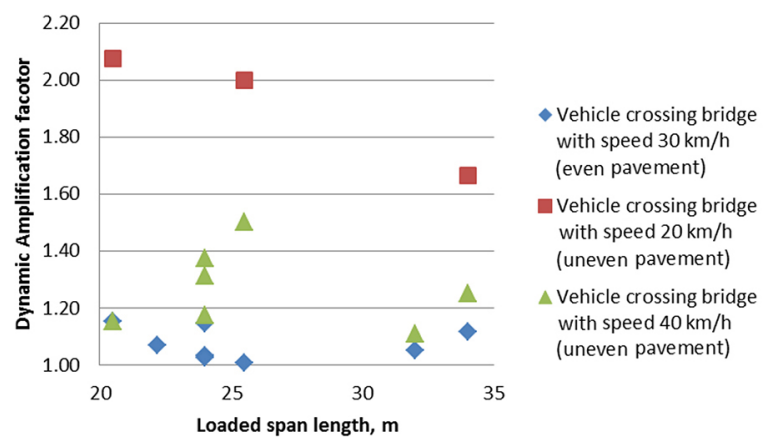

Fig. 19. DAF dependence on loaded length

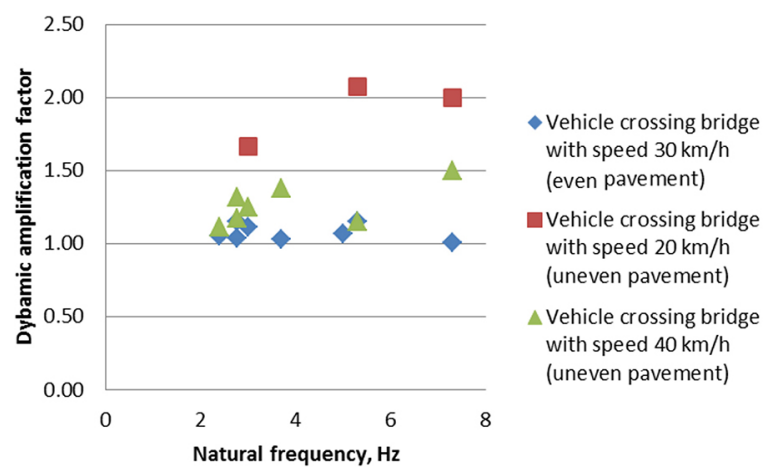

Fig. 20. DAF dependence on natural frequency

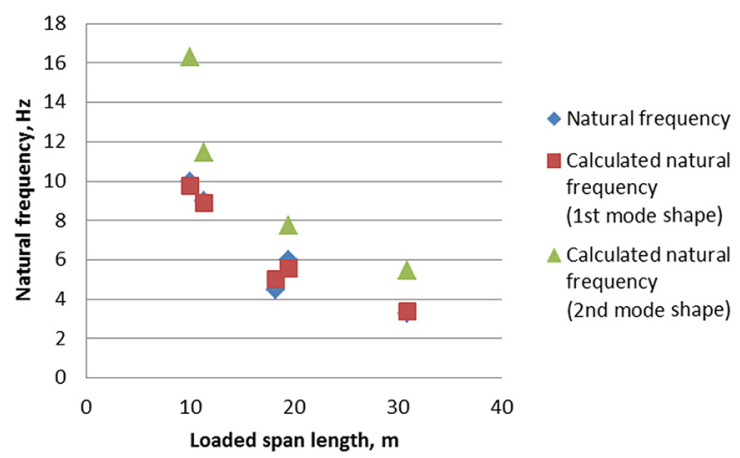

Fig. 21. Natural frequency dependence on span length
Natural frequency for structures were calculated using FEM software LIRA and calculated results for first mode shape are given in Table 2.

Figure 21 shows that for reinforced concrete slab bridges natural frequency decrease when span length increase. Measured natural frequency for two bridges exceeded $1^{\text {st }}$ mode frequency, but all frequencies were smaller than $2^{\text {nd }}$ mode shape frequencies.

Figure 22 shows Dynamic amplification factor dependence on the loaded length. It can be seen that also for reinforced concrete slab bridges DAF did not depend only on span length, but there are many other factors, that influence this parameter. Moreover, Figure 22 shows DAF values at different vehicle crossing speeds. This show that for uneven pavement DAF values will be higher than for even pavement and that lower vehicle speed will increase DAF values.

Figure 23 shows that increasing bridge natural frequency decrease DAF values. Figure 22 and Figure 23 show that for uneven pavement DAF values increase also this value significantly depend on vehicle speed. For lower speeds DAF is much higher hence it much more influence bridge deterioration speed however this tendency is not to well displayed as it is for prestressed concrete bridges.

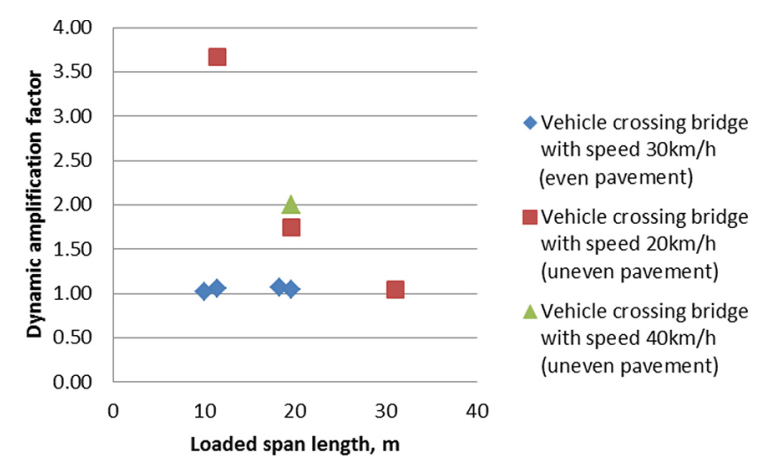

Fig. 22. DAF dependence on loaded span length

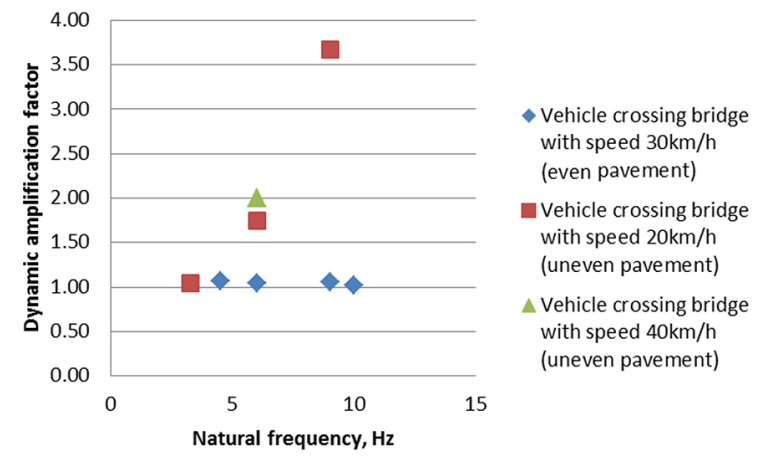

Fig. 23. DAF dependence on Natural frequency 


\section{Conclusions}

Obtained results show that DAF values for reinforced concrete and prestressed concrete bridges does not depend only on span length but there are many other factors that influence DAF. Results show that for bridges road surface condition is a very important factor. If road surface has ice bumps in the winter or potholes then heavy traffic driving with low speed can significantly increase deterioration of bridge structure.

Bridge natural frequency did not correlate with the bridge span length for pre-stressed concrete bridges, however for simple concrete bridges there was a tendency for natural frequency to decrease when span length increased. However there was a correlation between natural frequency and DAF - for higher natural frequency values DAF values were smaller.

Overall DAF values for even pavement were within range 1.0 to 1.4 and are in the range proposed in the Eurocode 1. Hence proposed values are reasonable for good pavement condition.

Because of the DAF value correlation with evenness of the bridge pavement, there should be regular bridge maintenance to assure good pavement conditions of all time hence significantly large DAF values can decrease load carrying capacity of the bridge.

\section{Acknowledgments}

The research leading to these results has received the funding from Latvia state research programme under grant agreement "Innovative and multifunctional composite materials for sustainable buildings".

\section{References}

Akimovs, E.; Paeglītis, A. 2010. Tiltu pārbaude ar slodzi Latvijā, Latvijas būvniecība 5: 52-54.

Beards, C. F. 1996. Structural vibration: analysis and damping. Butterworth-Heinemann, 150-152.

Brady, S. P.; O’Brien, J. O.; Znidaric, A. 2006. Effect of vehicle velocity on the dynamic amplification of a vehicle crossing a simply supported bridge, Journal of Bridge Engineering 11(2): 241-249.

http://dx.doi.org/10.1061/(ASCE)1084-0702(2006)11:2(241)
Brencic, A.; Sabia, D. 2007. Tanaro Bridge: dynamic tests on a couple of Spans, Journal of Bridge Engineering 12(5): 662-665. http://dx.doi.org/10.1061/(ASCE)1084-0702(2007)12:5(662)

Bruls, A.; Calgaro, J. A.; Mathieu, H.; Prat, M. 1996. ENV1991 Part 3: the main models of traffic loads on bridges: background studies. IABSE Colloquim, Delft. The Delft: IABSE, 215-228.

Burdet, O.; Corthay, S. 1995. Dynamic load testing of Swiss bridges, IABSE Symposium San Francisco, Extending the Lifespan of Structures 73(2): 1123-1128. San Francisko: IABSE.

Cantero, D.; González, A.; O’Brien, E. J. 2009. Maximum dynamic stress on bridges traversed by moving loads, Proceedings of the ICE - Bridge Engineering 162(BE2): 75-85. http://dx.doi.org/10.1680/BREN.2009.162.2.75

Cebon, D. 1999. Handbook of vehicle-road interaction. London: Taylor \& Francis.

Cunha, A.; Caetano, E.; Magalhaes, F. 2008. Output-only dynamic testing, Structural Concrete 8(2): 67-85. http://dx.doi.org/10.1680/stco.2007.8.2.67

EN 1991-2:2003. Eurocode 1: Actions on structures - Part 2: Traffic loads on bridges. European standard.

Fryba, L. 1996. Dynamics of railway bridges. London: Thomas Telford. http://dx.doi.org/10.1680/dorb.34716

Gonzalez, A.; Znidaric, A.; Casas, J. R.; Enright, B.; O’Brien, E.; Lavric, I.; Kalin, J. 2009. Recommendations on dynamic amplification allowance ARCHES-22-DE10. Warszawa.

Gonzalez, A.; Rattigan, P.; O’Brien, E. J.; Caprani, C. C. 2008. Determination of bridge lifetime dynamic amplification factor using finite element analysis of critical loading scenarios, Engineering Structures 30(9): 2330-2337. http://dx.doi.org/10.1016/j.engstruct.2008.01.017

Karoumi, R.; Andersson, A. 2007. Load testing of the new Svinesund Bridge. Stockholm: Royal Institute of Technology (KTH).

LVS 190-11: 2009. Bridge inspection and load testing(in Latvian).

O’Brien, E. J.; Rattigan, P.; Gonzalez, A.; Dowling, J.; Znidaric, A. 2009. Characteristic dynamic traffic load effects in bridges, Engineering Structures 31: 1607-1612. http://dx.doi.org/10.1016/j.engstruct.2009.02.013

Paeglite, I.; Paeglitis, A. 2013. The dynamic amplification factor of the bridges in Latvia, Journal Procedia Engineering 57: 851-858. http://dx.doi.org/10.1016/j.proeng.2013.04.108

Paeglitis, An.; Paeglitis, Ai. 2012. Investigation and upgrading of a historical multispan arch masonry Bridge, in F. Biondini, D. M. Frangopol (Eds.). Bridge maintenance, safety, management, resilience and sustainability. London: Taylor\&Francis Group, 1086-1093. ISBN 978-0-415-62124-3.

Paulter, P.; Chaallai, O.; Proulx, J. 1992. Bridge dynamics and dynamic amplification factors - a review of analytical and experimental findings, Canadian Journal of Civil Engineering 19: 260-278. http://dx.doi.org/10.1139/192-032

SNIP 2.05.03-84:1986. Bridges and pipes. Russian building regulations. (in Russian).

Ilze PAEGLITE, PhD student in Riga Technical University, Faculty of Civil Engineering. Research about dynamic load effects on bridge structure.

Ainars PAEGLITIS, Professor, Dr Sc. ing., Head of Department of Roads and Bridges in Riga Technical University. Research about bridge durability.

Juris SMIRNOVS, Professor, Dr Sc. ing., Head of Faculty of Civil Engineering in Riga Technical University. Research about traffic safety and road pavements. 